\title{
Correction to: Routine Sildenafil Does Not Improve Clinical Outcomes After Fontan Operation
}

\author{
J. Leslie Gaddis Collins ${ }^{1} \cdot$ Mark A. Law ${ }^{1} \cdot$ Santiago Borasino ${ }^{2} \cdot$ W. Clinton Erwin ${ }^{3} \cdot$ David C. Cleveland $^{4}$. \\ Jeffrey A. Alten ${ }^{2,5}$
}

Published online: 25 January 2018

○) Springer Science+Business Media, LLC, part of Springer Nature 2018

\section{Correction to: Pediatr Cardiol (2017) 38:1703-1708 https://doi.org/10.1007/s00246-017-1716-4}

The original version of this article unfortunately contained a mistake. The presentation of Table 2 was incorrect . The corrected Table 2 is given below.

The original article can be found online at https://doi.org/10.1007/ s00246-017-1716-4.

Jeffrey A. Alten

jalten@peds.uab.edu

1 Division of Pediatric Cardiology, University of Alabama at Birmingham, Birmingham, AL 35233, USA

2 Division of Pediatric Cardiology, Section of Cardiac Critical Care, University of Alabama at Birmingham, Birmingham, AL 35233, USA

3 School of Medicine, University of Alabama at Birmingham, Birmingham, AL 35233, USA

4 Division of Cardiothoracic Surgery, University of Alabama at Birmingham, Birmingham, AL 35233, USA

5 Section of Pediatric Cardiac Critical Care Medicine, University of Alabama at Birmingham, 1600 5th Avenue South, Children's Park Place Suite 210, Birmingham, AL 35233, USA 


\begin{tabular}{lccc}
\hline Outcome & No sildenafil & Sildenafil & \\
& $N=84$ & $N=19$ & \\
\hline Total 5\% albumin, 24 h (mL/kg) & $17(1,30)$ & $21(10,40)$ & 0.069 \\
Admit $\mathrm{SaO}_{2}(\%)$ & $97.5(93.7,98.4)$ & $98(94.7,100)$ & 0.145 \\
Inotrope score 12 h & $2.5(0,5)$ & $0(0,3)$ & 0.044 \\
Inotrope score 24 h & $0(0,0)$ & $0(0,0)$ & 0.262 \\
Maximum lactate (mg/dL) & $3.2(2.1,4.7)$ & $2.6(1.9,4.7)$ & 0.291 \\
Fluid balance 24 h (mL/kg) & $7.5(-12.4,29.3)$ & $3(-9.1,19.6)$ & 0.929 \\
Maximum serum creatinine (mg/dL) & $0.6(0.5,0.6)$ & $0.5(0.5,0.7)$ & 0.069 \\
Duration of MV (h) & $6.9(3.5,11.1)$ & $4(2,7)$ & 0.045 \\
Duration of $\mathrm{O}_{2}$ therapy (h) & $99(52,225)$ & $14.5(14,56)$ & 0.001 \\
Total CTO (mL/kg) & $83(49,132)$ & $126(59,256)$ & 0.058 \\
CTO (days) & $6(5,8)$ & $8(6,13)$ & 0.011 \\
Prolong CTO (\%) & $15 / 84(17.9)$ & $9 / 19(47.4)$ & 0.013 \\
LOS (days) & $9(7,11)$ & $13(8,25)$ & 0.016 \\
Prolong LOS (\%) & $18 / 84(21.4)$ & $6(31.6)$ & 0.010 \\
Readmission (\%) & $16(19)$ & & 0.229 \\
\hline
\end{tabular}

Data presented as median with interquartile range. All time points from cardiac intensive care unit admission

CTO chest tube output, $L O S$ length of stay 